Crystallization resistance of barium titanate zirconate ultrathin films from aqueous CSD: a study of cause and effect

Non Peer-reviewed author version

HARDY, An; Van Elshocht, Sven; Knaepen, Werner; D'HAEN, Jan; Conard, Thierry; Brijs, Bert; Vandervorst, Wilfred; Pourtois, Geoffrey; Kittl, Jorge; Detavernier, Christophe; Heyns, Marc; VAN BAEL, Marlies; VAN DEN RUL, Heidi \& MULLENS, Jules (2009) Crystallization resistance of barium titanate zirconate ultrathin films from aqueous CSD: a study of cause and effect. In: JOURNAL OF MATERIALS CHEMISTRY, 19(8). p. 1115-1122.

DOI: $10.1039 / \mathrm{B} 816856 \mathrm{C}$

Handle: http://hdl.handle.net/1942/9286 


\section{Crystallization resistance of barium titanate zirconate ultrathin films from aqueous CSD: a study of cause and effect}

An Hardy ${ }^{1,2,7}$, Sven Van Elshocht ${ }^{3}$, Werner Knaepen ${ }^{4}$, Jan D'Haen ${ }^{2,5}$, Thierry Conard ${ }^{3}$, Bert Brijs ${ }^{3}$, Wilfried Vandervorst ${ }^{3,6}$, Geoffrey Pourtois ${ }^{3}$, Jorge Kittl ${ }^{3}$, Christophe Detavernier $^{4}$, Marc Heyns ${ }^{3,6}$, Marlies Van Bael ${ }^{1,2}$, Heidi Van den Rul ${ }^{1,2}$, Jules Mullens ${ }^{1}$

1 Hasselt University, Institute for Materials Research, Laboratory of Inorganic and Physical Chemistry, Diepenbeek, Belgium

2 IMEC vzw, Division IMOMEC, Diepenbeek, Belgium 3 IMEC vzw, Heverlee, Belgium 4 Ghent University (UGENT), Gent, Belgium

5 Hasselt University, Institute for Materials Research, Diepenbeek, Belgium 6 Catholic University of Leuven, Heverlee, Belgium

7 XIOS Hogeschool Limburg, Department IWT, Diepenbeek, Belgium

\section{Graphical contents entry}

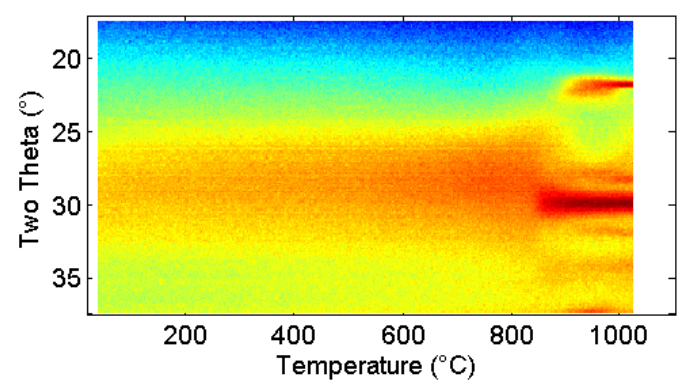

The dielectric properties of ultrathin film $\mathrm{BaZr}_{0.8} \mathrm{Ti}_{0.2} \mathrm{O}_{3}$, are explained by its crystallization behavior, which is linked to the films' chemical composition, to thickness effects, and to interfacial reactions with the substrate. 


\section{Summary}

Ultrathin $\mathrm{BaZr}_{0.8} \mathrm{Ti}_{0.2} \mathrm{O}_{3}$ films $(t<30 \mathrm{~nm})$ on $\mathrm{SiO}_{\mathrm{x}} / \mathrm{Si}$ substrates were obtained by means of aqueous chemical solution deposition. Though the precursor crystallized into cubic perovskite powder at $600^{\circ} \mathrm{C}$, ultrathin films only crystallized at 950 to $1000^{\circ} \mathrm{C}$, even after addition of $\mathrm{Ba}$ excess to compensate for loss of $\mathrm{Ba}$. Films with thickness above $100 \mathrm{~nm}$ on the other hand, crystallized readily around $650^{\circ} \mathrm{C}$. The crystallization is related to film thickness, affecting the crystallization activation energy, and to silicate formation by reaction with the substrate, exerting its largest influence in ultrathin films. Barium deficiency, silicate formation, carbonate secondary phase and the high activation energy for crystallization, resulted in the amorphous nature of the ultrathin films, which strongly affects the observed $k$ value $(\sim 15)$. The paper contributes insights with implications for the application of $\mathrm{BaZr}_{0.8} \operatorname{Ti}_{0.2} \mathrm{O}_{3}$ as an alternative high- $k$ gate dielectric.

Keywords: dielectrics ; interfaces ; in situ XRD ; ATR-FTIR ; Ba loss 


\section{Introduction.}

Downscaling the gate insulator in MOSFETs is one of the aspects of sustaining transistor miniaturization, at the heart of microelectronics' advancement. After having reduced the thickness of the traditional $\mathrm{SiO}_{\mathrm{x}}$ gate dielectric to its limits, the downscaling has continued lately by replacing the $\mathrm{SiO}_{\mathrm{x}}$ with alternative high- $k$ dielectrics such as $\mathrm{Hf}$ based materials ${ }^{1-4}$, among other efforts. After successful implementation of these second generation gate dielectrics in commercial applications, research has turned towards the identification of a third generation alternative "higher-k" dielectric, to keep up with the ever increasing demands imposed by the ITRS roadmap.

$\mathrm{BaZrO}_{3}$ has been proposed as a candidate material for application as alternative gate insulator, because of its relatively large dielectric constant (15-40 for bulk and thin films) and band gap of $5.3 \mathrm{eV}, 2 \mathrm{eV}$ larger than $\mathrm{BaTiO}_{3}{ }^{5-7}$, but so far did not receive a lot of attention. Substitution of $\mathrm{Zr}^{4+}$ by $\mathrm{Ti}^{4+}$ to form solid solutions of $\mathrm{Ba}(\mathrm{Zr}, \mathrm{Ti}) \mathrm{O}_{3}$ on the other hand, has been studied widely both for bulk and thin film samples, with applications as actuators, multilayer ceramic capacitors, dynamic random access memories and tunable microwave devices ${ }^{8}$. However, in the literature, focus has mainly been on the Ti rich side of the phase diagram. Reports on the dielectric properties of $\mathrm{Zr}$ rich compositions in bulk as well as thin film are scarce ${ }^{8,9}$. These, however, do indicate that substitution of a small amount of $\mathrm{Zr}^{4+}$ by $\mathrm{Ti}^{4+}$ can increase the dielectric constant. In order to avoid ferroelectric relaxor type behavior and maintain a temperature independent dielectric constant, the composition selected in the present work was $\mathrm{BaZr}_{0.8} \mathrm{Ti}_{0.2} \mathrm{O}_{3}$. This composition, being on the boundary between the compositional range of Ti-rich nanopolar clusters and relaxor ferroelectric behavior ${ }^{8,10}$, was reported to have a dielectric constant of $\sim 90$ for bulk ceramic and thin films on platinized silicon ${ }^{8,9}$, which is twice that of $\mathrm{BaZrO}_{3}$ itself. Furthermore, it is expected 
that the crystallization temperature for the solid solution will be lower than for $\mathrm{BaZrO}_{3}$, since the latter has a higher melting point $\left(2500^{\circ} \mathrm{C}^{11}\right)$ than $\mathrm{BaTiO}_{3}\left(1625^{\circ} \mathrm{C}^{11}\right)$. Size-effects, occurring when the crystallite size is reduced to the nanometer scale or when the film thickness is decreased, are known to have strong effects on the ferroelectric properties of $\mathrm{BaTiO}_{3}$ (see for example refs. ${ }^{12-14}$ ). Phase changes as well as interface contributions have also been observed to strongly affect the dielectric properties of high- $k$ dielectric materials when scaling down their thickness e.g. ${ }^{15}$. The range of film thicknesses in the final application as alternative high- $k$ dielectric for CMOS will be well below $30 \mathrm{~nm}$ (ultrathin films), which will therefore be the focus of the present work.

Previously, the advantages of using aqueous chemical solution deposition for the fabrication and screening of ultrathin dielectric oxide films have been reported ${ }^{16,17}$. It was shown that the $k$ values obtained from CSD films were equal to those for other deposition techniques, such as atomic layer deposition, which supports the use of this deposition technique for high $k$ films. The high stability, the close mixing of the metal ions and the subsequent good homogeneity of the precursor solutions can be expected to allow uncomplicated fabrication of multimetal oxides with a complex composition, such as $\mathrm{Ba}(\mathrm{Zr}, \mathrm{Ti}) \mathrm{O}_{3}$. This is one advantage compared to alkoxide sol-gel routes, where different hydrolysis rates depending on the metal ion can lead to phase separation. Other advantages are the low cost and the use of water instead of often teratogenic or harmful organic solvents.

To the best of our knowledge, there have been no reports on ultrathin films of $\mathrm{Ba}(\mathrm{Zr}, \mathrm{Ti}) \mathrm{O}_{3}$ on $\mathrm{SiO}_{\mathrm{x}} / \mathrm{Si}$ substrates in the literature. Here, we focus on the crystallization behavior of ultrathin $\mathrm{BaZr}_{0.8} \mathrm{Ti}_{0.2} \mathrm{O}_{3}$ films and give possible explanations and consequences thereof. 


\section{Results and discussion.}

\section{Crystallization of powders.}

To confirm the potential of the synthesized precursor to form the perovskite structured multimetal oxide, HT-XRD was carried out (Lynxeye setup, Error! Reference source not found.). Precalcined, amorphous $\mathrm{BaZr}_{0.8} \mathrm{Ti}_{0.2} \mathrm{O}_{3}$ (BZTO) precursor gels were heated in static air at a heating rate of $30^{\circ} \mathrm{C} / \mathrm{min}$, diffraction patterns were recorded every $50^{\circ} \mathrm{C}$ between 400 and $1000^{\circ} \mathrm{C}$. After cooling down, a diffraction pattern was recorded as well.

The stoichiometric precursor powder for $\mathrm{BaZr}_{0.8} \mathrm{Ti}_{0.2} \mathrm{O}_{3}$ crystallized into the perovskite oxide at a relatively low temperature between 550 and $600^{\circ} \mathrm{C}$. Note that our previous results indicated that $\mathrm{BaZrO}_{3}$ powder from a similar synthesis route, crystallizes only between 600 and $700^{\circ} \mathrm{C}^{18}$. All the diffraction peaks could be attributed to a single oxide phase showing high similarity to cubic $\mathrm{BaZrO}_{3}$ (JCPDS 06-0399 ${ }^{19}$ ). This shows that the small fraction of $\mathrm{BaTiO}_{3}$, as used here, forms a solid solution with the $\mathrm{BaZrO}_{3}$. The occurrence of $\mathrm{BaZr}_{0.8} \mathrm{Ti}_{0.2} \mathrm{O}_{3}$ as a solid solution system was reported for ceramics as well ${ }^{8}$. There is no splitting of the diffraction peaks at both high as well as room temperature, which demonstrates the cubic nature of the phase. No $\mathrm{BaCO}_{3}$ formation was observed for the stoichiometric precursor, within the detection limits of the technique.

Addition of an excess of $\mathrm{Ba}^{2+}(10$ or $20 \mathrm{~mol} \%)$ to the precursor led to a lowering of the crystallization temperature to between 500 and $550^{\circ} \mathrm{C}$. The higher the $\mathrm{Ba}^{2+}$ excess, the stronger the crystallinity at the same temperature. However, for all $\mathrm{Ba}^{2+}$ excess samples a $\mathrm{BaCO}_{3}$ secondary phase was observed as well, which crystallized together with the $\mathrm{BaZr}_{0.8} \mathrm{Ti}_{0.2} \mathrm{O}_{3}$. It remains present up to 800 or $900^{\circ} \mathrm{C}$ for the precursor containing 10 respectively $20 \% \mathrm{Ba}^{2+}$ excess. At higher temperatures the $\mathrm{BaCO}_{3}$ decomposes and 
disappears from the patterns. $\mathrm{BaO}$ is not observed, which could indicate that it is amorphous or that the $\mathrm{Ba}^{2+}$ excess is either incorporated into the crystal structure of the multimetal oxide or present as a $\mathrm{BaO}$ rich grain boundary phase ${ }^{20}$. On the other hand, a loss of Ba by evaporation would be another possible explanation (see below).

It is thus established that the presented aqueous synthesis route allows low temperature crystallization of the desired, complex oxide phase. Furthermore, an excess of $\mathrm{Ba}^{2+}$ was seen to lower the crystallization temperature by $\sim 50^{\circ} \mathrm{C}$, but also leads to formation of a thermostable $\mathrm{BaCO}_{3}$ secondary phase. The larger the $\mathrm{Ba}^{2+}$ excess, the higher the temperature at which the $\mathrm{BaCO}_{3}$ is removed.

\section{Crystallization of films.}

\section{Ultrathin films.}

The crystallization of ultrathin BZTO films, deposited from a $0.025 \mathrm{M}$ solution, with an ellipsometric thickness of $\sim 8 \mathrm{~nm}$, was studied with both HT-XRD setups. However, only the Vantec setup showed weak crystallization (Error! Reference source not found.a), beyond the sensitivity of the Lynxeye setup. A low intensity diffraction peak at ca. $29.8^{\circ} 2 \theta$ was observed starting from $\sim 950-1000^{\circ} \mathrm{C}$ and could be ascribed to the cubic perovskite BZTO phase.

It can be inferred that compared to the precursor powders, it is extremely difficult to crystallize $\mathrm{BaZr}_{0.8} \mathrm{Ti}_{0.2} \mathrm{O}_{3}$ ultrathin films $(0.025 \mathrm{M})$ on $\mathrm{SiO}_{\mathrm{x}} / \mathrm{Si}$ substrates at reasonable temperatures.

Next, the effect of $\mathrm{Ba}^{2+}$ excess addition to the precursor solution was studied. Based on the results for powders, a lowering of the crystallization temperature of the perovskite phase would be expected. Moreover, XPS and RBS determination of the composition of the nominal $\mathrm{BaZr}_{0.8} \mathrm{Ti}_{0.2} \mathrm{O}_{3}$ films, showed a lower $\mathrm{Ba}^{2+}$ content compared to the 
composition of the multimetal ion precursor solution, determined by ICP-AES. To verify this result, the measurements were carried out for nine other compositions as well. $0.025 \mathrm{M} \mathrm{Ba}(\mathrm{Zr}, \mathrm{Ti}) \mathrm{O}_{\mathrm{x}}$ precursor solutions containing nominally between 38.9 and $65.4 \% \mathrm{Ba}^{2+}[\mathrm{Ba} /(\mathrm{Ba}+\mathrm{Ti}+\mathrm{Zr})]$, between 23.1 and $55.6 \% \mathrm{Zr}^{4+}$ and between 3.6 and $18.8 \%$ of $\mathrm{Ti}^{4+}$ were prepared following the synthesis route in Error! Reference source not found.. The multimetal precursor solution composition was measured by ICP-AES and was found to be in good agreement with the nominal composition, with differences of maximum $0.5 \%$. Films were spin coated using these precursors and after thermal treatment, the composition was measured by XPS and RBS (Error! Reference source not found.). Angle resolved XPS measurements were performed as well and did not show any significant change of the cation composition with respect to depth. The error bars for XPS results are set to $1 \%$ of the concentration value. These represent the statistical error on the measurement and were determined by a long term repeatability test on our instrument. Analysis of two replica films with nominal composition $\mathrm{BaZr}_{0.8} \mathrm{Ti}_{0.2} \mathrm{O}_{3}$, yielded highly similar results ( $\mathrm{Ba}-\mathrm{Zr}$ - Ti 36 - 54 - 10 and 34 - 56 - 10\%), confirming the reproducability of the measurements and deposition process. The error for the RBS compositions, as dictated by the error in the stopping power, which is experimentally determined, is set to $10 \%$ as a broad estimate. The general reproducibility of these measurements amounts to $5 \%$.

From this extended XPS and RBS study, it could be concluded that $\mathrm{Ba}^{2+}$ deficiency in the films compared to the precursor, is observed consistently for all the compositions studied (Error! Reference source not found.).

A large error in the ICP-AES determination of the precursor solution is not probable. There is the indirect evidence that the precursor gels prepared from the same solutions did yield phase pure BZTO powders, while the perovskite structure is not expected to 
tolerate large $\mathrm{Ba}^{2+}$ vacancies ${ }^{20}$. Due to the low film thickness (around $8 \mathrm{~nm}$ ) and the improbability of $\mathrm{Ba}^{2+}$ diffusing into the Si substrate beyond the sensitivity region of the XPS and certainly RBS, it is unlikely that the $\mathrm{Ba}^{2+}$ "disappears" from the film by reaction with or diffusion into the substrate. Hence, the most probable explanation is a loss of $\mathrm{Ba}^{2+}$ during the deposition and /or thermal treatment process. Evaporative loss of barium has indeed been reported occasionally in literature for $\mathrm{YBa}_{2} \mathrm{Cu}_{3} \mathrm{O}_{6+\mathrm{x}}$ superconductors and proton conducting perovskites ${ }^{20-22}$. Loss of $\mathrm{Ba}^{2+}$ by reaction with the alumina crucible ${ }^{23}$ is unlikely, since there is no direct contact between the films and the crucible. In the present study, the evaporation at relatively low temperature $\left(600^{\circ} \mathrm{C}\right)$ could be enhanced by the extremely large surface to volume ratio related to the very low film thickness.

To compensate for this effect and try to lower the BZTO crystallization temperature, a $20 \% \mathrm{Ba}^{2+}$ excess was added to the precursor $(0.025 \mathrm{M})$, since the loss amounts to this. The film, prepared by heat treatment up to $480^{\circ} \mathrm{C}$ on hot plates, was observed to crystallize around $950-1000^{\circ} \mathrm{C}$ in the Vantec setup through the appearance of a diffraction peak at $29.9^{\circ} 2 \theta$ (Error! Reference source not found.b). In summary, a large Ba deficiency in the films in comparison to the precursor solutions was demonstrated. To compensate for this effect, $\mathrm{Ba}^{2+}$ excess was added to the precursor solution. It did not modify the crystallization behavior of the ultrathin films, which still remained amorphous up to extremely high temperatures of approximately $950-1000^{\circ} \mathrm{C}$.

Crystallization behavior as a function of film thickness.

The film thickness is known, both from experimental results as well as modelling, to affect the crystallization kinetics of thin films. Thicker films crystallize faster during an 
isothermal period, when considering volume induced crystallization ${ }^{24}$. The experimental results shown here suggest that the activation energy, for the crystallization of BZTO, is increased strongly in ultrathin films, compared to powders. To verify this, the crystallization behavior of films with higher thickness was studied with HT-XRD. The samples were 4 layered films deposited from a $0.1 \mathrm{M}$ precursor, with a thickness of $28 \mathrm{~nm}$, as well as 4 and 8 layered films, deposited from a $0.4 \mathrm{M}$ precursor solution, with an estimated thickness of 100 and $200 \mathrm{~nm}$, based on the thickness equation in the experimental section.

For films deposited from a stoichiometric precursor solution with a concentration of 0.1 $\mathrm{M}$, no crystallization was observed, nor for $10 \%, 20 \%$ or $30 \%$ of $\mathrm{Ba}^{2+}$ excess, using the Lynxeye HT-XRD setup (not shown).

For the highest film thicknesses ( $\sim 100$ and $200 \mathrm{~nm})$ crystallization was observed in the Lynxeye HT-XRD setup at the low temperatures of respectively between 650 and $700^{\circ} \mathrm{C}$ (Error! Reference source not found.a) or $600^{\circ} \mathrm{C}$ to $650^{\circ} \mathrm{C}$ (not shown). On the other hand, in the Vantec setup a much higher crystallization temperature, between 850 $-900^{\circ} \mathrm{C}$ was observed (Error! Reference source not found.b). The difference in crystallization temperature is attributed to kinetic factors connected with the different heating profiles in both setups, being either intermittent or continuous. Secondly, there might also be an effect of the ambient, being either static air or flowing He. For comparison, Ti-rich BZTO films with thicknesses of 100-150 nm, deposited by sol-gel on platinized silicon substrates, have been reported to be crystalline after $4 \mathrm{~h}$ anneal at $550^{\circ} \mathrm{C}^{25}$

Based on the presence of the $(110) \mathrm{Ba}(\mathrm{Zr}, \mathrm{Ti}) \mathrm{O}_{3}$ peak at $\sim 30^{\circ} 2 \theta$, which is the strongest reflection, it is concluded that the perovskite phase is formed. This phase remains stable up to at least $950-1000^{\circ} \mathrm{C}$. The results demonstrate that thin films $(t>100 \mathrm{~nm})$ 
can crystallize into the desired perovskite phase, even when deposited from stoichiometric precursor solutions onto $\mathrm{SiO}_{\mathrm{x}} / \mathrm{Si}$ substrates.

Since film thicknesses above $100 \mathrm{~nm}$ are shown to be easily crystallized at relatively low temperatures, it can be inferred that the very low film thickness is related to the crystallization resistance of ultrathin BZTO films. Possibly, this can be partially explained by the effect of Ba loss, which can be expected to be more severe for the thinner films due to their larger surface/volume ratio, and which could affect their crystallization behavior. This effect, however, merely adds to the strong effect of a higher activation energy for crystallization of ultrathin BZTO films compared to thin films.

Furthermore, in the literature an increase of the crystallization temperature is observed of Hf based dielectrics ${ }^{26}$, when silicates are deposited, or of rare earth oxides and scandates ${ }^{27-29}$, when silicates are formed through interfacial reaction. For $\mathrm{SrTiO}_{3}$ films a Ti rich interfacial layer, consisting of $\mathrm{TiSiO}_{\mathrm{x}}$ and $\mathrm{TiSi}_{2}$ has been reported ${ }^{30}$. Furthermore, possibility of intermixing or silicate formation at the interface of $(\mathrm{Ba}, \mathrm{Sr}) \mathrm{TiO}_{3}$ and $\mathrm{BaO}$ films with $\mathrm{Si}$ substrates is described ${ }^{31-33}$. The amorphicity of $\mathrm{BaZrO}_{3}$ at $500^{\circ} \mathrm{C}$ was ascribed to the formation of an interfacial layer, either $\mathrm{SiO}_{2}$ or $\mathrm{SiC}$ in ${ }^{34}$. Therefore, we studied the interfacial layer between $\mathrm{BaZr}_{0.8} \mathrm{Ti}_{0.2} \mathrm{O}_{3}$ and the $\mathrm{Si}$ substrate using GATR-FTIR.

GATR-FTIR spectra were measured for 4 layered films deposited from $0.025 \mathrm{M}, 0.1$ and $0.4 \mathrm{M}$ and an 8 layered film deposited from the $0.4 \mathrm{M}$ stoichiometric precursor solutions for $\mathrm{BaZr}_{0.8} \mathrm{Ti}_{0.2} \mathrm{O}_{3}$ (Error! Reference source not found.). For tetragonal $\mathrm{BaTiO}_{3}$, infrared modes at 491, 175, 184 and $12 \mathrm{~cm}^{-1}$ are expected, while for cubic $\mathrm{BaZrO}_{3}$ vibrations are expected at 505, 210 and $115 \mathrm{~cm}^{-1} 35$. However, these vibrations are out of the measurable range of the GATR-FTIR $\left(4000-600 \mathrm{~cm}^{-1}\right)$, since it is 
equipped with a Ge crystal. The assignment of the bands observed at $\sim 700$ and $605 \mathrm{~cm}^{-}$ ${ }^{1}$ is not trivial. Note that by comparison with a reference spectrum recorded for a commercial $\mathrm{BaCO}_{3}$ powder, it is concluded that these bands are not due to the carbonate. Possibly, they can be ascribed to M-O vibrations in the amorphous solid. Very strong silicate formation is evidenced by the increased intensity of the region around $1070 \mathrm{~cm}^{-1}$, where Ba-O-Si, Zr-O-Si and possibly Ti-O-Si vibrations can be expected $^{36,37}$. Ti-O-Si bands can also occur at lower wavenumbers $\left(920 \mathrm{~cm}^{-138}\right)$. The intensity of this band relative to the $\mathrm{SiO}_{\mathrm{x}}$ longitudinal optic (LO) band around $1240 \mathrm{~cm}^{-}$ ${ }^{1}$, clearly increases with increasing film thickness for the 4 layered films. The decrease of the Si-O-Si LO band intensity around $1240 \mathrm{~cm}^{-1}$ could be due to consumption of $\mathrm{SiO}_{\mathrm{x}}$ by reaction with the $\mathrm{BaZr}_{0.8} \mathrm{Ti}_{0.2} \mathrm{O}_{3}$ film leading to silicate formation, or to the screening of the signal by the deposited film. For the 8 layered film no $\mathrm{SiO}_{\mathrm{x}}$ nor M-O-Si bands are detected. This can be attributed to the large film thickness, inhibiting penetration of the beam down to the substrate, allowing to probe only the surface of the deposited film. Around $1420 \mathrm{~cm}^{-1}$ carbonate is detected for all the films. The formation of $\mathrm{BaCO}_{3}$ during chemical solution deposition of barium containing oxide films is a well-known issue in literature ${ }^{39}$. The splitting of the band, could be ascribed to the formation of a mixed carbonate, with $\mathrm{Ba}^{2+}$ as well as $\mathrm{Zr}^{4+}$ and/or $\mathrm{Ti}^{4+}{ }^{40}$ or to the presence of a bicarbonate, analogous to lanthanum bicarbonate in ${ }^{41}$. Due to its high thermal stability, the carbonate can only be removed after annealing up to high temperatures. This was confirmed by our results on $\mathrm{BaZrO}_{3}$ films (not shown): after annealing at $800^{\circ} \mathrm{C}$ in air, the $\mathrm{BaCO}_{3}$ vibration at $1400 \mathrm{~cm}^{-1}$ disappeared. However, also an increase of the interfacial silicate was observed. As FTIR spectrometry is highly sensitive to the detection of carbonates, the amount of $\mathrm{BaCO}_{3}$ is not necessarily large, which explains 
why it was not observed in the HT-XRD measurements. On the other hand, it is not excluded that it is present as an amorphous phase.

In summary, it was shown that extensive silicate formation occurs by reaction between barium zirconate titanate thin films and $\mathrm{SiO}_{\mathrm{x}} / \mathrm{Si}$ substrates even at the moderate annealing temperature of $600^{\circ} \mathrm{C}$. This may also be an important factor in the crystallization resistance of perovskite BZTO ultrathin films. Besides reaction with the substrate, the presence of a thermostable $\mathrm{BaCO}_{3}$ secondary phase was shown. Annealing can aid in its removal, but will adversely affect the interfacial reaction.

\section{Dielectric properties of ultrathin $\mathrm{BaZr}_{0.8} \mathrm{Ti}_{0.2} \mathrm{O}_{3}$ films.}

The electrical characterization was limited to films in a thickness range relevant for the targeted application of these alternative high- $k$ materials. The $C-V$ curves, measured at $10 \mathrm{kHz}$, of films with ellipsometric thicknesses between 4 and $28 \mathrm{~nm}$, were fitted using the Hauser routine. The extracted EOT (equivalent oxide thickness) values were plotted against the physical thickness (Error! Reference source not found.a). Error bars indicate the range of EOT values, obtained by measurement of 5-10 capacitors, with different topelectrode areas ${ }^{42}$. From the slope of this plot, which is equal to $3.9 / k$, an accurate determination of the dielectric constant of the films is possible. The $k$-value was determined to be 14.8 (range 14.6-15.4) for $\mathrm{BaZr}_{0.8} \mathrm{Ti}_{0.2} \mathrm{O}_{3}$ films, deposited using the stoichiometric precursor, and 12.4 (range 12.1-13.7) for the $20 \%$ Ba excess precursor. The $k$-value ranges indicated, were based on the range of the EOT values for the different capacitors on each sample. These values are close to the permittivity that was obtained for $\mathrm{BaZrO}_{3}$ films ( $\left.k=15\right)$, deposited by aqueous CSD and annealed at $650^{\circ} \mathrm{C}$

43. They are low in comparison to the values expected based on literature of thicker 
films and bulk ceramics ${ }^{8}$. This can be explained by the lack of crystallization, leading to a higher molecular volume which decreases $k$ e.g. ${ }^{44}$. Furthermore, the absence of long range ordering prevents formation of polar clusters of $\mathrm{BaTiO}_{3}$, which are reponsible for the expected effects of $\mathrm{Ti}^{4+}$ addition on $\mathrm{BaZrO}_{3}$ in this compositional region ${ }^{8}$. This leads to the similarity of the $k$ value of $\mathrm{BaZr}_{0.8} \mathrm{Ti}_{0.2} \mathrm{O}_{3}$ to $\mathrm{BaZrO}_{3}$ films deposited by the same route. On the other hand, $k$ values of 15 have also been reported for bulk $\mathrm{BaZrO}_{3}$, which was dependent on the porosity ${ }^{6}$. This also could be a supplemental factor in our amorphous films, possibly having lower density than that of crystalline material.

The leakage current was very low for all the films, lying in the noise level for the thickest films, and being slightly higher for the thinnest films (Error! Reference source not found.b). Error bars here reflect the range of the leakage current at $\mathrm{V}_{\mathrm{FB}}-2.5 \mathrm{~V}$ obtained on the different devices.

Anneal treatment at high temperature or for prolonged periods of time, would be beneficial to enhance the crystallinity and remove the carbonate. However, at least 950 $-1000^{\circ} \mathrm{C}$ is needed according to the study of the crystallization behavior, which would enhance the interfacial silicate formation and $\mathrm{Ba}^{2+}$ loss. These expectations were confirmed by $k$-value determination of $\mathrm{BaZrO}_{3}$ films after annealing at $900{ }^{\circ} \mathrm{C}$ (not shown). After $1 \mathrm{~min}$ annealing the $k$-value remained 15, while longer annealing times led to very high leakage and low dielectric breakdown voltages.

In short, the electrical results for the ultrathin films with thickness below $30 \mathrm{~nm}$, deviate from bulk and thin film (>100 nm) properties in the literature. This can be attributed, at least in part, to the films amorphicity and concurrent possible lack of densification, the presence of the silicates and the minor carbonate secondary phase, based on the results 
presented in the previous paragraphs. Compensating for barium deficiency by addition of an excess to the precursor leads to a status quo of the $k$ value.

\section{Experimental.}

The precursor synthesis was carried out analogously to the synthesis detailed in an earlier publication ${ }^{18}$, where we reported the preparation of aqueous $\mathrm{BaZrO}_{3}$ precursor solutions. Here, $\mathrm{Ba}(\mathrm{Zr}, \mathrm{Ti}) \mathrm{O}_{3}$ precursor solutions were prepared by mixing the $\mathrm{BaZrO}_{3}$ precursor solution with a citratoperoxo-Ti(IV) precursor solution prepared as reported earlier in the publication ${ }^{45}$. A schematic of the entire synthesis procedure is given in Error! Reference source not found.. $\mathrm{BaCO}_{3}$ (Aldrich, 99.999\%), $\mathrm{Zr}(\mathrm{IV})$-propanolate solution in propanol (Fluka, 70\%), citric acid $\mathrm{C}_{6} \mathrm{H}_{7} \mathrm{O}_{8}$ (Aldrich, 99\%) and $\mathrm{NH}_{3}$ (aq) (Merck, 32\%, extra pure) were used. The concentration of the mono- and multimetal ion solutions was measured using ICP-AES (Perkin Elmer, Optima 3000).

On the one hand, the precursor solutions were evaporated in Petri dishes in an airflushed laboratory furnace $\left(60^{\circ} \mathrm{C}\right)$ for gelation. Next, the gels were precalcined $\left(200^{\circ} \mathrm{C}\right)$ as a preparation for high-temperature X-ray diffraction measurement (HT-XRD).

On the other hand, (ultra)thin films were obtained by spin coating the precursor solutions onto $1.2 \mathrm{~nm} \mathrm{SiO}_{\mathrm{x}} / \mathrm{Si}$ substrates $\left(2.5 \times 2.5 \mathrm{~cm}^{2}\right)$, cleaned beforehand with sulfuric acid peroxide and ammonia peroxide mixtures. The rotation speed was set to $3000 \mathrm{rpm}$ for $30 \mathrm{~s}$ with an acceleration of $1000 \mathrm{rpm} / \mathrm{s}$. The precursor films were decomposed by subsequent hot plate treatment in ambient air at $260^{\circ} \mathrm{C}$ and $480{ }^{\circ} \mathrm{C}$, for two minutes each. Each film consisted of 4 layers deposited subsequently, unless mentioned otherwise. These films were subjected to HT-XRD measurement or given a final anneal by placing them in $\mathrm{Al}_{2} \mathrm{O}_{3}$ ignition boats and inserting them into a preheated 
tube furnace $\left(600^{\circ} \mathrm{C}, 30 \mathrm{~min}, 0.5 \mathrm{~L} / \mathrm{min}\right.$ synthetic dry air) to prepare them for other characterizations.

The film thickness is controlled by adjusting the precursor concentration. Besides the $0.1 \mathrm{M}$ solution, also dilutions thereof $(0.010,0.025$ and $0.050 \mathrm{M})$ were prepared with water. This yielded film thicknesses between 5 and $30 \mathrm{~nm}$, where the film thickness, $t$ $(\mathrm{nm})$, increased linearly with the precursor concentration, $c$ (in $\mathrm{mol} / \mathrm{L}$ ):

$$
t=(266 c+1.2) \mathrm{nm}
$$

Alternatively, higher concentration precursor solutions of $0.4 \mathrm{M}$ were prepared as well, simply by less dilution in the last synthesis step of Error! Reference source not found.. HT-XRD was carried out on a Bruker D8 diffractometer, in an Anton Paar heating module in static air and using a position sensitive detector equipped with 192 detector strips (Bruker, Lynxeye), $\mathrm{Cu} \mathrm{K}_{\alpha}$ radiation and a step size of $0.04^{\circ} 2 \theta$. Continuous heating at $30{ }^{\circ} \mathrm{C} / \mathrm{min}$ is alternated with isothermal periods (ca. $8 \mathrm{~min}$ ) at prior defined temperatures, during which XRD patterns are recorded from 10 to $60^{\circ} 2 \theta$ with acceptable counting statistics. This setup will be designated "Lynxeye setup". The setup was used successfully for the study of ultrathin films before ${ }^{16}$. In a second setup, a different position sensitive detector (Bruker, Vantec) was used, spanning $20^{\circ} 2 \theta$ at once, and heating occurred in a home-built heating chamber using a dynamic He ambient ("Vantec setup"). This setup allows recording XRD patterns, with a step size of $0.014^{\circ} 2 \theta$, on-line during heating every $1.5 \mathrm{~s}$, avoiding the need for isothermal steps. The $2 \theta$ range selected for the measurements was 17.5 to $37.5^{\circ} 2 \theta$. Whereas the Lynxeye setup allows a complete overview of the diffraction pattern because of the wider $2 \theta$ range, the Vantec setup provides even higher sensitivity and time resolution. 
The films were further characterized by p-polarized Glancing angle Attenuated Total Reflectance - Fourier transform infrared (GATR - FTIR, Harrick - Bruker Vertex 70, resolution $\left.=4 \mathrm{~cm}^{-1}\right)$. Single wavelength ellipsometry, using a single layer model and a refractive index of 1.75 , was applied for film thickness measurements. Capacitance and leakage current - voltage ( $C-V$ and $I-V)$ was measured on Pt topelectrodes deposited by evaporation through a shadow mask (between $1.5 \mathrm{E}-3$ and $5.0 \mathrm{E}-4 \mathrm{~cm}^{2}$ ) using a Keithley 4200 semiconductor characterization system. X-ray Photoelectron Spectroscopy (XPS, Theta300, Thermo Instruments, monochromatized Al $\mathrm{K}_{\alpha}$ photon beam, with standard sensitivity factors for quantification of the composition) was applied for the compositional analysis as well as Rutherford Backscattering Spectroscopy (RBS, beam energy $1 \mathrm{MeV}, \mathrm{He}^{+}$, scatter angle $165^{\circ}$, solid angle $0.4 \mathrm{mSR}$ and dose of $20 \mu \mathrm{C}$ ). The results were expressed as atom\%. The XPS measurements were performed in angle integrated mode between 22 and 78 degree, as measured from the normal of the sample.

\section{Conclusion.}

Ultrathin $\mathrm{BaZr}_{0.8} \mathrm{Ti}_{0.2} \mathrm{O}_{3}$ films have been deposited onto $\mathrm{SiO}_{\mathrm{x}} / \mathrm{Si}$ substrates for the first time, by aqueous chemical solution deposition. The films' material and electrical properties were characterized in view of their application as alternative high- $k$ dielectrics. It is clearly shown that ultrathin film properties deviate largely from what is expected based on bulk and thin film properties. This underlines the importance of material evaluation in the thickness range of the final application and the lasting necessity of a fast and flexible deposition route, as aqueous CSD, to be able to evaluate many different materials. As our previous research has shown that CSD films can yield equal properties to e.g. ALD films, it may be inferred that this behavior is intrinsic to 
$\mathrm{BaZr}_{0.8} \mathrm{Ti}_{0.2} \mathrm{O}_{3}$, and that the results obtained here could transfer to other deposition techniques as well.

The fundamental study presented in this work, yields an improved insight into the crystallization resistance of ultrathin $\mathrm{BaZr}_{0.8} \mathrm{Ti}_{0.2} \mathrm{O}_{3}$ films, the material related causes for it and its effects on the electrical properties.

\section{Acknowledgements.}

A. Hardy and M.K. Van Bael are postdoctoral research fellows of the Research Foundation - Flanders (FWO-Vlaanderen). This research is supported by the FWO research project G.0273.05 and G.0177.03. 


\section{References.}

1 R. Katamreddy, R. Inman, G. Jursich, A. Soulet, C. Takoudis, Acta Mater., 2008, 56, 710-718.

2 Y. Yamamoto, K. Kita, K. Kyuno, A. Toriumi, Appl. Phys. Lett., 2006, 89, 032903.

3 O. Sharia, A. A. Demkov, G. Bersuker, B. H. Lee, Phys. Rev. B, 2008, 77, 085326.

4 M. Bohr, R. Chau, T. Ghani, K. Mistry, IEEE Spectrum, 2007, 44, 29-35.

5 T. Matsui, Y. Kitano, N. Fujimura, K. Morii, T. Ito, Jpn. J. Appl. Phys. - Part 1, 2002, 41, 6639-6642.

6 A. M. Azad, S. Subramaniam, Mater. Res. Bull., 2002, 37, 11-21.

7 J. Robertson, J. Vac. Sci. Tech. B, 2000, 18, 1785-1791.

8 T. Maiti, R. Guo, A. S. Bhalla, J. Am. Ceram. Soc., 2008, 91, 1769-1780.

9 T. Tohma, H. Masumoto, T. Goto, Jpn. J. Appl. Phys. Part 1, 2002, 41, $6643-$ 6646.

10 X. J. Chou, J. W. Zhai, H. T. Jiang, X. Yao, J. Appl. Phys., 2007, 102, 084106.

11 D. R. Lide, Ed. CRC Handbook of Chemistry and Physics - 83rd edition; CRC Press, 2002-2003.

12 J. Junquera, P. Ghosez, Nature, 2003, 422, 506-509.

13 D. D. Fong, G. B. Stephenson, S. K. Streiffer, J. A. Eastman, O. Auciello, P. H. Fuoss, C. Thompson, Science, 2004, 304, 1650-1653.

14 M. Dawber, K. M. Rabe, J. F. Scott, Rev. Mod. Phys., 2005, 77, 1083-1130.

15 P. S. Lysaght, J. C. Woicik, M. A. Sahiner, P. D. Kirsch, G. Bersuker, B. H. Lee, R. Jammy In 2008 International Symposium On Vlsi Technology, Systems And Applications (Vlsi-Tsa), Proceedings Of Technical Program; Ieee: New York, 2008, p 156-157.

16 A. Hardy, S. Van Elshocht, C. Adelmann, T. Conard, A. Franquet, O. Douhéret, I. Haeldermans, J. D'Haen, S. De Gendt, M. Caymax, M. Heyns, M.

D'Olieslaeger, M. K. Van Bael, J. Mullens, Thin Solid Films, 2008, 516, 83438351.

17 S. Van Elshocht, A. Hardy, C. Adelmann, M. Caymax, T. Conard, A. Franquet, O. Richard, M. K. Van Bael, J. Mullens, S. De Gendt, J. Electrochem. Soc., 2008, 155, G91-G95.

18 A. Hardy, J. D'Haen, H. Van den Rul, M. K. Van Bael, J. Mullens, Mater. Res. Bull., 2008, in press.

19 JCPDS, 1997, Powder diffraction file of inorganic phases, Joint Committee on Powder Diffraction Standards, Swarthmore.

20 S. M. Haile, G. Staneff, K. H. Ryu, J. Mater. Sci., 2001, 36, 1149-1160.

21 J. Wu, L. P. Li, W. T. P. Espinosa, S. T. Haile, J. Mater. Res., 2004, 19, 23662376.

22 R. Platzer, R. Schwenker, A. Fuessel, D. W. Tom, J. Tate, J. A. Gardner, W. E. Evenson, J. A. Sommers, Hyperfine Interact., 1997, 110, 271-286.

23 C.-J. Kim, K.-B. Kim, I.-H. H. Kuk, G-W., Mater. Sci. Engin. B, 1996, 39, $25-$ 33.

24 V. I. Trofimov, I. V. Trofimov, J. I. Kim, Thin Solid Films, 2006, 495, 398-403.

25 L. G. A. Marques, L. S. Cavalcante, A. Z. Simoes, F. M. Pontes, L. S. SantosJunior, M. Santos, I. L. V. Rosa, J. A. Varela, E. Longo, Mater. Chem. Phys., 2007, 105, 293-297. 
26 G. D. Wilk, R. M. Wallace, J. M. Anthony, J. Appl. Phys., 2000, 87, 484-492.

27 R. Lo Nigro, R. G. Toro, G. Malandrino, G. G. Condorelli, V. Raineri, I. L. Fragala, Adv. Funct. Mater., 2005, 15, 838-845.

28 R. Thomas, P. Ehrhart, M. Luysberg, M. Boese, R. Waser, M. Roeckerath, E. Rije, J. Schubert, S. Van Elshocht, M. Caymax, Appl. Phys. Lett., 2006, 89, 232902.

29 C. Adelmann, S. Van Elshocht, A. Franquet, T. Conard, O. Richard, H. Bender, P. Lehnen, S. De Gendt, Appl. Phys. Lett., 2008, 92, 112902.

30 L. V. Goncharova, D. G. Starodub, E. Garfunkel, T. Gustafsson, V. Vaithyanathan, J. Lettieri, D. G. Schlom, J. Appl. Phys., 2006, 100, 014912.

31 V. Craciun, D. Craciun, N. D. Bassim, J. M. Howard, R. K. Singh In Perovskite Materials; Materials Research Society: Warrendale, 2002. Vol. 718, p 257-262.

32 P. D. Kirsch, J. G. Ekerdt, J. Vac. Sci. Technol. A-Vac. Surf. Films, 2001, 19, 207-214.

33 M. Copel, Appl. Phys. Lett., 2008, 92, 152909.

34 Y. Kitano, T. Matsui, N. Fujimura, K. Morii, T. Ito, J. Cryst. Growth, 2002, 243, 164-169.

35 C. H. Perry, D. J. McCarthy, G. Rupprecht, Phys. Rev., 1965, 138, A1537A1538.

36 S. Katayama, N. Yamada, M. Awano, J. European Ceram. Soc., 2004, 24, 421425.

37 J. J. Yu, I. W. Boyd, Thin Solid Films, 2004, 453-54, 215-218.

38 Z. M. Wang, Q. Fang, J. Y. Zhang, J. X. Wu, Y. Di, W. Chen, M. L. Chen, I. W. Boyd, Thin Solid Films, 2004, 453-54, 167-171.

39 F. Boschini, B. Robertz, A. Rulmont, R. Cloots, J. Eur. Ceram. Soc., 2003, 23, 3035-3042.

40 K. Nakamoto. Infrared and Raman Spectra of Inorganic and Coordination Compounds Part B: Applications in Coordination, Organometallic, and Bioinorganic Chemistry, 5th edition ed.; John Wiley \& Sons, Inc.: New York, 1997.

41 H. Vidal, S. Bernal, R. T. Baker, D. Finol, J. A. P. Omil, J. M. Pintado, J. M. Rodriguez-Izquierdo, J. Catal., 1999, 183, 53-62.

42 S. Van Elshocht, A. Hardy, T. Witters, C. Adelmann, M. Caymax, T. Conard, S. De Gendt, A. Franquet, M. Heyns, M. K. Van Bael, J. Mullens, Electrochem. Solid State Lett., 2007, 10, G15-G17.

43 A. Hardy, S. Van Elshocht, J. D'Haen, S. De Gendt, M. K. Van Bael, M. Heyns, M. D'Olieslaeger, J. Mullens. Materials Science of High k Dielectric StacksFrom Fundamentals to Technology (Mater. Res. Soc. Symp. Proc. Volume 1073E, Warrendale, PA, 2008).

44 O. Engström, B. Raeissi, S. Hall, O. Buiu, M. C. Lemme, H. D. B. Gottlob, P. K. Hurley, K. Cherkaoui, Sol.-State Electr., 2007, 51, 622-626.

45 A. Hardy, J. D'Haen, M. K. Van Bael, J. Mullens, J. Sol-Gel Sci. Technol., 2007, 44, 65-74. 


\section{Figure captions}

Error! Reference source not found.

Error! Reference source not found.

Error! Reference source not found.

Error! Reference source not found.

Error! Reference source not found.

Error! Reference source not found.

Error! Reference source not found. 